patients have eye injury; there is no information about the number with permanently impaired vision. Our experience is that eye injury is sustained from fragments, mud, or sand thrown up by the explosion. Many victims lose one eye and have a variable degree of injury to the other; a minority are totally blinded.

The incidence of other disabilities in these patients is certainly higher than indicated here. Numerous nerve palsies are not documented, probably because they represent only one aspect of the successful salvage of a severely injured limb.

There is little information about the number of patients who discharged themselves from hospital. We are sure that this is quite a small number. The commonest reason for leaving hospital against medical advice is the cultural or religious unacceptability of amputation; some patients prefer to die. Had these patients remained in hospital there would have been a slightly higher number of eventual amputations.

This study focuses on the surgical aspects of antipersonnel mine injuries; one must bear in mind that the prospects for amputees in developing countries may be divorce, unemployment, or crime. The effect on the society of several thousand amputees may be considerable. The ICRC runs rehabilitation centres in many countries and worldwide produces 9000 prostheses a year, most of which are for victims of antipersonnel mines.

We thank Mr Heinz Weiler, Ms Ariane Curdy, and Ms Irene Deslarzes for their invaluable help with the database of this study.

1 Jones EL, Peters AF, Gasior RM. Early management of battle casualties in Vietnam. Arch Surg 1968:97:1-15.

2 Cheng XM, Lin YQ, Guo RF, Lian WK, Wang DT. Analysis of wound ballistics in 2414 cases of battle casualties. F Trauma 1990;6(suppl): 169-72. 3 Coupland RM. Amputation for antipersonnel mine injuries of the leg: preservation of the tibial stump using a medial gastrocnemius myoplasty. Ann R Coll Surg Engl 1989;71:405-8.

4 Adams DB, Schwab CW. Twenty one year experience with land mine injuries. f Trauma 1988;28(suppl):S159-62.

5 Traverso LW, Fleming A, Johnson DE, Wongrukmitr B. Combat casualties in northern Thailand: emphasis on land mine injuries and levels of amputation. Milit Med 1981;146:682-5.

(Accepted 26 September 1991)

\section{Dogs that bite}

\author{
P C Shewell, J D Nancarrow
}

\section{Abstract}

Objective-To study the circumstances of dog bites and identify risk factors.

Design-Postal questionnaire survey and case note review of victims of dog bites referred between 1982 and 1989.

Setting-One referral based regional plastic surgery unit.

Patients - 146 consecutive patients referred for TABLE I-Number of patients sustaining dog bites, according to age, September 1982-September 1989

\begin{tabular}{lr}
\hline Age (years) & No \\
\hline $0-$ & 25 \\
$5-$ & 30 \\
$10-$ & 24 \\
$15-$ & 10 \\
$20-$ & 5 \\
$25-$ & 6 \\
$30-$ & 1 \\
$35-$ & 13 \\
$40-$ & 5 \\
$45-$ & 5 \\
$50-$ & 7 \\
$55-$ & 5 \\
$60-$ & 2 \\
$65-$ & 3 \\
$70-$ & 3 \\
$75-$ & 2 \\
$\geqslant 80$ & 1 \\
\hline
\end{tabular}

West Midlands Regional Plastic and Jaw Surgery Unit, Wordsley Hospital, Wordsley, Stourbridge,

West Midlands

P C Shewell, FRCS, senior house officer

J D Nancarrow, FRCs, consultant plastic surgeon

Correspondence to Mr P C Shewell,

Royal Orthopaedic Hospital, The Woodlands, Northfield, Birmingham B31 2AP.

BMf 1991;303:1512-3 primary treatment of dog bites, for whom current addresses were available for $133,107(81 \%)$ of whom returned the questionnaire.

Results - The male to female ratio was $74: 72 ; 79$ (54\%) patients were aged below 15 years. The commonest dogs producing bites were Staffordshire bull terriers (15 cases), Jack Russell terriers (13), medium sized mongrels (10), and Alsatians (nine). 82 of $96(85 \%)$ dogs were male. 29 of $47(62 \%)$ adults were bitten at home and 45 of $60(75 \%)$ children at a friend's, neighbour's, or relative's house. 91 of 107 $(85 \%)$ bites occurred in the dog's home. Bites occurred during playing with $13(12 \%)$, petting 14 $(13 \%)$, or waking $16(15 \%)$ dogs. $45(42 \%)$ bites were judged as unprovoked. 32 bites were identified as severe and 11 attacks as sustained.

Conclusions-Most victims are bitten by male dogs which they either own or have had frequent contact with, and the bite occurs in the dog's home.

\section{Introduction}

The subject of dog bites has increasingly come to the forefront of public attention in recent months, generating much heated comment and opinion. We therefore decided to review patients with dog bites treated at the West Midlands Regional Plastic Surgery Unit to identify any risk factors associated with these injuries.

\section{Methods}

We examined the records of patients referred to the unit from September 1982 to September 1989 for treatment of dog bites and sent a questionnaire to each patient or to parents of patients aged under 15 years.
Questions concerned the place and circumstances of the bite, details of the dog, action taken, and the patient's (and parent's) subsequent attitude to the injuries and to dogs.

\section{Results}

Of 146 patients referred to the unit, all but three required out of hours surgery; the average length of stay was four days. No annual or seasonal variation in the number of bites was noted. The male to female ratio was $74: 72$ and $79(54 \%)$ were aged under 15 years (table I). The injuries consisted of 76 puncture wound and 304 lacerations, 81 of which involved loss of tissue. One hundred and twenty six $(86 \%)$ patients had injuries to their face or head.

Current addresses were available for 133 patients, and $107(81 \%)$ patients replied to the questionnaire Patients or their parents were asked to score both their injuries and the resultant scars; table II shows the replies. When asked about their present reaction to dogs $23(38 \%)$ children and nine (19\%) adults stated that they were nervous of dogs and $37(62 \%)$ children and $27(57 \%)$ adults that they were more cautious of them (average time from being bitten was $3 \cdot 4$ years).

TABLE II-Scoring of wounds and scars from dog bites in children and adults. Figures are numbers (percentages)

\begin{tabular}{lcclcr}
\hline & \multicolumn{2}{c}{ Wounds } & & \multicolumn{2}{c}{ Scars } \\
\cline { 2 - 3 } \cline { 5 - 6 } Severity & $\begin{array}{c}\text { Children } \\
(\mathbf{n}=59)\end{array}$ & $\begin{array}{c}\text { Adults } \\
(\mathbf{n}=47)\end{array}$ & & $\begin{array}{c}\text { Children } \\
(\mathbf{n}=59)\end{array}$ & $\begin{array}{c}\text { Adults } \\
(\mathbf{n}=47)\end{array}$ \\
\hline Minor & $2(3)$ & $8(17)$ & & $29(49)$ & $27(57)$ \\
Moderate & $22(37)$ & $20(43)$ & & $21(36)$ & $14(30)$ \\
Severe & $36(61)$ & $19(40)$ & & $10(17)$ & $6(13)$ \\
\hline
\end{tabular}

Figure 1 shows the breeds of dog responsible. When known, in 82 of $96(85 \%)$ bites the dogs were male and in 22 of $82(27 \%)$ they had had obedience training; in 36 of $53(68 \%)$ bites to children and 24 of $43(56 \%)$ bites to adults the dog was subsequently destroyed by the owners. Of 38 dogs subsequently kept by their owners, $7(18 \%)$ bit again.

Twenty nine $(62 \%)$ adults were bitten at home by 


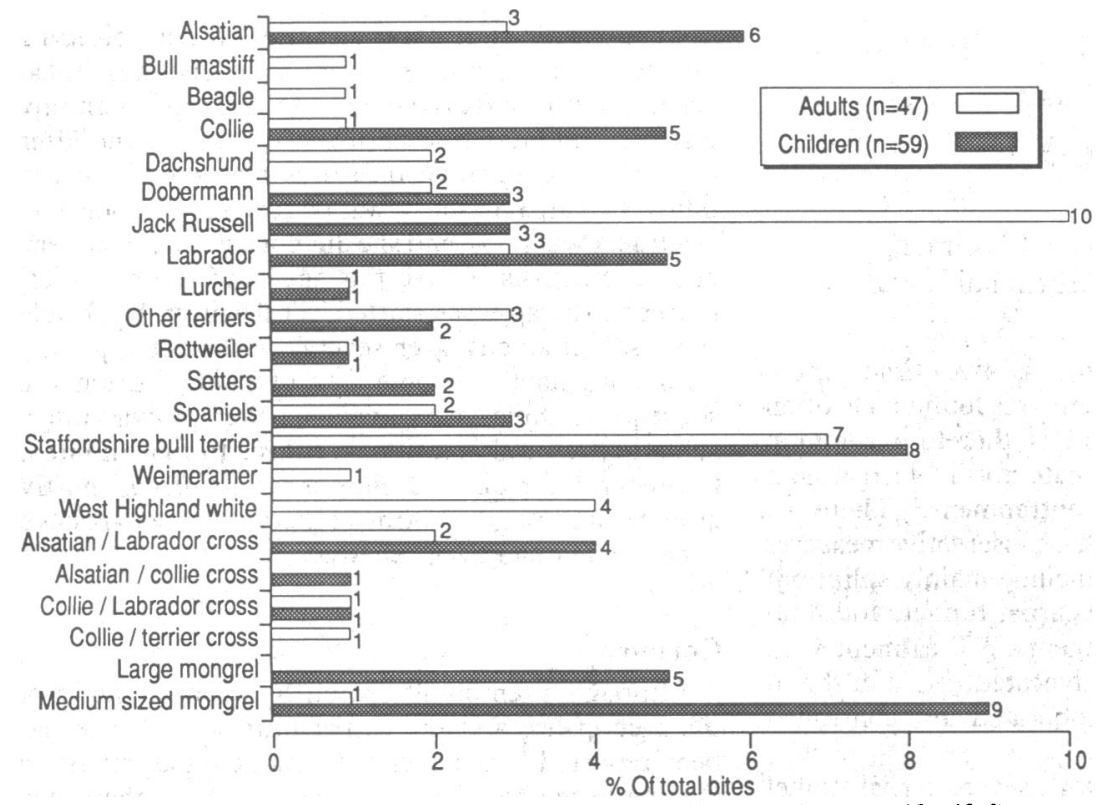

FIG 1-Breeds of dog responsible for injuries in 107 adults and children (one dog was unidentified)

their own dogs whereas 45 (75\%) children were bitten at the house of a relative, neighbour, or friend, usually where they were frequent visitors. Typically the attack occurred soon after their arrival, often when the child approached the dog to pet it. Ninety one $(85 \%)$ bites occurred in the owner's home. An appreciable number of bites occurred when playing with $(13,12 \%)$, petting $(14,13 \%)$, or waking dogs $(16,15 \%)$. In half of children's bites and almost a third of adults' bites the attacks were judged to be "unprovoked."

A separate group, comprising 32 severe bites was identified with the following criteria: subjective judgment by the victim or parents; lacerations on more than two areas of the face or body; more than $1 \mathrm{~cm}^{2}$ of tissue loss; and damage to underlying structures-for example, bone, tendons, and orbit. Attacks were judged to be severe if they fell into at least two of these four categories. Eleven bites also involved sustained attacks. Figure 2 shows the breeds responsible for severe injuries and sustained attacks.

FIG 2-Breeds of dog responsible for sustained attacks and severe injuries

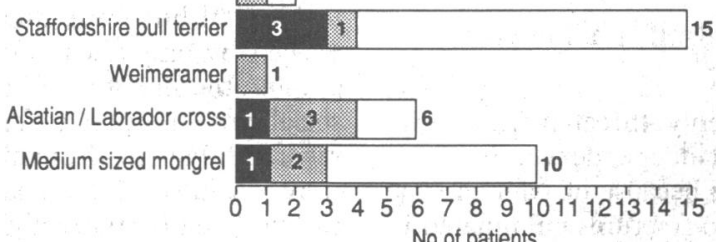

\section{Discussion}

There have been several recent reviews of the treatment of dog bites ${ }^{1-3}$ but little attention to their aetiology or prevention, even though dog bites are a common problem..$^{4-6}$

Our patients represent a selected group requiring treatment in a plastic surgery unit. The age groups and sex ratios correspond to those in other series, but a seasonal variation was not found in our study ${ }^{67}$; the anatomical distribution of bites also matches other series from plastic surgery units. ${ }^{18}$

The dogs offending most commonly were Staffordshire bull terriers, Jack Russell terriers, medium sized mongrels, Alsatians, and Labradors, all of which are common breeds in this locality. Interestingly, Dobermann pinschers and Rottweilers were responsible for only $7 \%$ of bites. Sustained attacks tend to be caused by Alsatians, Dobermann pinschers, and Staffordshire bull terriers. The number of such attacks may well rise with the apparent increase in the popularity of large attack and guard type breeds, as has happened in the United States. ${ }^{9}$

Lauer et al reported a $48 \%$ rate of "unprovoked" attacks on children. ${ }^{4}$ There seemed to be common features in many of our cases. We identified four types of circumstances leading to attack: victim "invading" the dog's territory; victim seen as a threat to the dog's "family"; victim seen as a threat to the dog; and jealous dog.

Being bitten by a dog obviously has psychological and physical sequelae, particularly in children aged under $10,31(79 \%)$ of whom were subsequently nervous of dogs. The extensive replies received from parents showed that their emotional reaction to the incidents often seemed far greater than that of their children; many parents expressed feelings of guilt and shame. Seventeen per cent (10/59) of children and $13 \%$ $(6 / 47)$ of adults rated their physical scars as severe.

In conclusion, dog bites are a common problem that have physical and psychological effects on the victim and on the parents of child victims. In most cases the victim either owns the dog or is well known to it, and the attack occurs in the dog's home. Certain situations seem to be dangerous - for example, approaching or bending over dogs, especially if they are lying quietly approaching them immediately after entering their territory; teasing or waking them; or playing with them till they become overexcited. An underlying reason was evident in many bites that were judged by the victims to be unprovoked; if the public were more aware the number of these unfortunate injuries might be reduced.

1 Palmer J, Rees M. Dog bites of the face: a 15 year review. Br $\mathcal{F}$ Plast Surg 1983;36:315-8.

2 Thomas PR, Buntine JA. Man's best friend? A review of the Austin hospital's experience with dog bites. Med f Aust 1987;147:536-40.

3 Zackowski D, Lehman JA, Tantri DP. Management of dog bite avulsions of the lip vermilion. Pediatr Emerg Care 1986;2:85-7.

4 Lauer EA, White WC, Lauer BA. Dog bites. A neglected problem in accident prevention. Am f Dis Child 1982;136:202-4.

5 Carithers HA. Mammalian bites of children: a problem of accident prevention. Am F Dis Child 1958;95:150-6.

6 Hervey E. Incidence of bites due to dogs and other animals in Leeds. BMF 1977;ii:53-4.

Cun YT, Berkelhamer JE, Herold TE. Dog bites in children less than 4 years old Pediatrics 1982;69:119-20.

8 Barclay TL. Dog bites of the face. Br I Plast Surg 1956;9:34-7.

9 Baack BR, Kucan JO, Demarest G, Smoot JC. Mauling by pit bull terriers: case ack BR, Kucan JO, Demarest $G$,

(Accepted 3 October 1991) 